\title{
Functional emergence of a column-like architecture in layer 5 of mouse somatosensory cortex in vivo
}

\author{
Kyo Koizumi ${ }^{1} \cdot$ Masatoshi Inoue ${ }^{2,3} \cdot$ Srikanta Chowdhury $^{3,4} \cdot$ Haruhiko Bito $^{2,3} \cdot$ Akihiro Yamanaka $^{3,4} \cdot$ Toru Ishizuka $^{1}$. \\ Hiromu Yawo ${ }^{1,5}$ iD
}

Received: 14 December 2017 / Accepted: 30 April 2018 / Published online: 14 May 2018

(c) The Physiological Society of Japan and Springer Japan KK, part of Springer Nature 2018

\begin{abstract}
To investigate how the functional architecture is organized in layer 5 (L5) of the somatosensory cortex of a mouse in vivo, the input-output relationship was investigated using an all-optical approach. The neural activity in L5 was optically recorded using a $\mathrm{Ca}^{2+}$ sensor, R-CaMP2, through a microprism inserted in the cortex under two-photon microscopy, while the L5 was regionally excited using optogenetics. The excitability was spread around the blue-light irradiated region, but the horizontal propagation was limited to within a certain distance $(\lambda<130 \mu \mathrm{m}$ from the center of the illumination spot). When two regions were photostimulated with a short interval, the excitability of each cluster was reduced. Therefore, a column-like architecture had functionally emerged with reciprocal inhibition through a minimal number of synaptic relays. This could generate a synchronous output from a region of L5 with simultaneous enhancement of the signal-to-noise ratio by silencing of the neighboring regions.
\end{abstract}

Keywords Optogenetics $\cdot \mathrm{Ca}^{2+}$ imaging $\cdot$ Two-photon microscopy $\cdot$ Self-organization $\cdot$ Column $\cdot$ Reciprocal inhibition

\section{Introduction}

Generally, the mammalian neocortex consists of six layers, each of which is characterized by its cellular and network organization [1]. Neurons in each layer are also distinguished

Electronic supplementary material The online version of this article (https://doi.org/10.1007/s12576-018-0618-4) contains supplementary material, which is available to authorized users.

Hiromu Yawo

hiromu.yawo.c7@tohoku.ac.jp

1 Department of Developmental Biology and Neuroscience, Tohoku University Graduate School of Life Sciences, 2-1-1 Katahira, Aoba-ku, Sendai 980-8577, Japan

2 Department of Neurochemistry, Graduate School of Medicine, University of Tokyo, Tokyo, Japan

3 Core Research for Evolutional Science and Technology (CREST), Japan Science and Technology Agency, Tokyo, Japan

4 Department of Neuroscience II, Research Institute of Environmental Medicine, Nagoya University, Nagoya, Japan

5 Center for Neuroscience, Tohoku University Graduate School of Medicine, Sendai, Japan by their functional connectivity $[2,3]$. For example, in the primary somatosensory cortex (S1), the major layer 4 neurons receive thalamic inputs and project locally to other layers such as layer $2 / 3$. On the other hand, the layer 5 (L5) pyramidal neurons produce major outputs to other cortical as well as subcortical regions. In other words, the L5 is a primary cortical layer involved in the integration of various sensory modalities as well as the top-down control of other brain regions.

Some regions of the neocortex are also functionally organized in a columnar fashion. That is, neurons having similar response properties are often perpendicularly arrayed through layers. For example, in the primary visual area (V1), neurons with similar orientational/directional preference are grouped together, forming a column of $0.1-0.5 \mathrm{~mm}$ in width, and are segregated in distribution from other neurons of different preferences $[4,5]$. During development, it has been computationally predicted and experimentally revealed that the spatiotemporal balance between excitatory and inhibitory connections in the local circuitry is one of the determinants of generating the regularly spaced columnar organization in V1 $[6,7]$. Similarly, the functional architecture of the adult neocortex is presumed to be organized by the excitatory-inhibitory balance [8-10]. The cortical L5 
consists of the excitatory pyramidal neurons and the inhibitory interneurons of various subclasses with a characteristic morphological, molecular and electrophysiological feature [11-13]. However, because of the technical difficulties, it remains to be elucidated how the individual neurons are orchestrated to organize the functional architecture in the in vivo cortex [14].

In the present study, the computational processing in the L5 network of mouse S1 was characterized by the input-output relationship. The neural activity was optically recorded while the L5 was regionally excited using optogenetics. Our all-optical approach revealed the functional emergence of a column-like cluster of active L5 neurons that were surrounded by inactive neurons, and that the column-like clusters inhibited each other. It is suggested that the excitatory projecting neurons and inhibitory interneurons form a circuitry of reciprocal inhibition to sculpture the output signals exiting from the L5.

\section{Materials and methods}

\section{Animals}

All experiments were carried out using wild-type C57BL/6 J mice (female, 8-12 weeks old, 20-30 gBW) in accordance with the animal experiment protocol approved by Tohoku University Committee for Animal Experiments (Approval no. 2017LsA-002) under the guidelines for Animal Experiments and Related Activities of Tohoku University as well as the guiding principles of the Physiological Society of Japan and the National Institutes of Health (NIH), USA. The number of animals in this study was kept to a minimum and, when possible, all animals were anesthetized to minimize their suffering. Animals had access to food and water ad libitum and were kept under a 12-h light-dark cycle.

\section{Viral vectors}

Adeno-associated virus (AAV) Helper-Free System (Agilent Technologies, Inc., Santa Clara, CA, USA) was used for the generation of the AAV-CaMKII-C1V1-Venus (DJ) viral vector. The purification method was modified from a previously published protocol [15]. Briefly, HEK293 cells were transfected with a pAAV-CaMKII-C1V1-Venus vector plasmid, pHelper and pAAV-RC (serotype DJ; purchased from Cell Biolabs Inc, San Diego, CA, USA), using a standard calcium phosphate method. Three days after transfection, cells were collected and suspended in artificial cerebrospinal fluid (ACSF) containing (in mM) $124 \mathrm{NaCl}, 3 \mathrm{KCl}, 26$ $\mathrm{NaHCO}_{3}, 2 \mathrm{CaCl}_{2}, 1 \mathrm{MgSO}_{4}, 1.25 \mathrm{KH}_{2} \mathrm{PO}_{4}, 10$ D-glucose. Following multiple freeze-thaw cycles, the cell lysates were treated with benzonase nuclease (Merck, Darmstadt,
Germany) at $37^{\circ} \mathrm{C}$ for $30 \mathrm{~min}$, and centrifuged 2 times at $16,000 \mathrm{~g}$ for $10 \mathrm{~min}$ at $4{ }^{\circ} \mathrm{C}$. The supernatant was used as the virus-containing solution. Quantitative PCR was performed to measure the titer of purified virus. Virus aliquots were then stored at $-80^{\circ} \mathrm{C}$ until use in the experiment.

The AAV1-CAG-R-CaMP2-WPRE-SV40poly was produced using the baculovirus-Sf9 expression system as previously described [16]. Briefly, the baculoviruses with the AAV construct and those with the RepCap1 helper construct were co-infected into $\mathrm{Sf} 9$ cells in a suspension culture. After 2-4 days, the cells were treated with a hypotonic lysis buffer [1\% Triton X-100, $10 \mathrm{mM}$ HEPES (pH 8.0), $3 \mathrm{mM} \mathrm{NaCl}$ and $0.5 \mathrm{mM} \mathrm{MgCl}_{2}$ ] for $15 \mathrm{~min}$ at room temperature. After inactivating the baculoviruses, the lysate was centrifuged and the supernatant was mixed with AVB Sepharose (GE Healthcare UK Ltd. Little Chalfont, England) for $1 \mathrm{~h}$ at room temperature. By applying this mixture to a gravity-flow column (Bio-Rad Laboratories, Inc., Hercules, CA, USA), the viruses were eluted using an elution buffer $(50 \mathrm{mM}$ glycine at $\mathrm{pH}$ 3.0) and were further concentrated using Amicon Ultra $100 \mathrm{~K}$ Centrifugal Concentrators (EMD Millipore-Merck KGaA, Darmstadt, Germany) with PBS. The final virus titer was $1.0 \times 10^{13} \mathrm{gc} / \mathrm{ml}$.

\section{Immunohistochemistry}

Cortical neurons were isolated from embryonic day-16 ICR mice (Japan SLC Inc., Shizuoka, Japan) using Nerve-Cells Dispersion Solutions (Sumitomo Bakelite, Tokyo, Japan) according to the manufacturer's instructions, and grown in culture medium (Sumitomo Bakelite) under a 5\% $\mathrm{CO}_{2}$ atmosphere at $37{ }^{\circ} \mathrm{C}$, and the viral solution containing AAVCaMKII-C1V1-Venus viruses was diluted in the culture medium $\left(1 / 1000\right.$, finally $7 \times 10^{10}$ copies $\left./ \mathrm{ml}\right) 7$ days in vitro (DIV). The cultured tissues were fixed with $4 \%$ paraformaldehyde (room temperature, $30 \mathrm{~min}$ ) at $18 \mathrm{DIV}$ and served for the immunohistochemistry.

After washing 3 times with phosphate buffer solution (PBS), the specimens were reacted with anti-GFP (rat serum, 1:250, 04404-84, Nacalai) and either anti-pan CaMKII (rabbit serum, 1:250, gift from Dr. Kohji Fukunaga, Tohoku University) or anti-GABA (rabbit serum, 1:250, A2052, Sigma-Aldrich, St. Louis, MO) followed by secondary antibodies conjugated with Alexa Fluor 546 (goat anti-rabbit IgG, 1:250, A11081, Thermo Fisher Scientific, Waltham, MA) and Alexa Fluor 488 (goat anti-rat IgG, 1:250, A11006, Thermo Fisher Scientific), respectively.

To evaluate the co-expression of CaMKII or GABA in the Venus-positive neurons, 10 fields (each $344,000 \mu^{2}$ ) were selected randomly and viewed under a conventional epi-fluorescent microscope with 20× objective lens (Axiovert200, Carl Zeiss, Oberkochen, Germany) and the filter system either set at 17 (Alexa Fluor 488: excitation, $485 \pm 20 \mathrm{~nm}$; 
dichroic mirror, $510 \mathrm{~nm}$; emission, $515-565 \mathrm{~nm}$ ) or set at 20 (Alexa Fluor 546: excitation, $546 \pm 12 \mathrm{~nm}$; dichroic mirror, $560 \mathrm{~nm}$; emission, 575-640 nm), and imaged using a cooled CCD camera system (VB-7010, KEYENCE CO, Osaka, Japan).

\section{Surgical procedures}

After administration of the anti-inflammatory agents, dexamethasone sodium phosphate $(1.3 \mathrm{mg} / \mathrm{kgBW}$, Banyu Pharmaceutical Co Ltd., Tokyo, Japan), sulfadiazine (24 mg/ kgBW, Kyoritsu Seiyaku, Tokyo, Japan), trimethoprim $(4.8 \mathrm{mg} / \mathrm{kgBW}$, Kyoritsu Seiyaku) and carprofen $(6 \mathrm{mg} / \mathrm{kg}$, Pfizer Inc., New York City, USA), the mice were anesthetized by intraperitoneal injection of a ketamine-xylazine mixture (50 mg/kgBW ketamine, Daiichi Sankyo Co. Ltd., Tokyo, Japan and $10 \mathrm{mg} / \mathrm{kgBW}$ xylazine, Sigma-Aldrich, St. Louis, MO, USA). The skull was exposed, attached with a head chamber (CP-2, Narishige Inc., Tokyo, Japan) using glue (Loctite 4011, Henkel Co. Rocky Hill, CT06067, USA), and a hole was drilled (diameter, $3 \mathrm{~mm}$ ) over the cortex $\mathrm{S} 1$ region at $2 \mathrm{~mm}$ lateral and $1 \mathrm{~mm}$ caudal from the bregma while being cleaned with physiological saline. The viral solution (R-CaMP2: $1.0 \times 10^{13} \mathrm{gc} / \mathrm{ml}, \mathrm{C} 1 \mathrm{~V} 1: 2.0 \times 10^{13}$ $\mathrm{gc} / \mathrm{ml}$ ) was injected at $0.5 \mu \mathrm{l} / \mathrm{min}$ using a glass pipette (tip diameter, $20 \mu \mathrm{m}, \mathrm{G}-1.5$, Narishige) that was siliconized with chlorotri-n-butylsilane (Alfa Aesar, Massachusetts, USA), into the cortex at 500-700 $\mu \mathrm{m}$ below the surface in a region without obviously large blood vessels. The reflectorcoated microprism (Micro prism $1 \times 1 \times 1$, Nippon Electric Glass Co. Ltd., Otsu, Japan) was inserted (Fig. 1a, b) in order to see the rostral aspect of the coronary incision (width, $1 \sim 1.5 \mathrm{~mm}$; depth, $1 \sim 1.5 \mathrm{~mm}$ ) made by a microblade (377615, Beaver-Visitec International, Inc., Waltham, MA 02452 USA) and covered by a round cover glass (diameter, $2.7 \mathrm{~mm}$; Matsunami Glass IND., Ltd., Osaka, Japan) with a head chamber (CP-2, Narishige) that was glued on the skull (Loctite 4011, Henkel). The mice recovered from the anesthesia on a heater (MP-914-NV, Vivaria Co., Osaka, Japan) while being administered intraperitoneally physiological saline containing 5\% glucose $(0.1 \mathrm{ml})$ for hydration and nutrition, returned to the cage and kept for 1 month with food and water containing antibacterial agents $(0.6 \%$, Shinoral ${ }^{\circledR}$, Boehringer Ingelheim, Ingelheim, Germany).

\section{Photostimulation}

To illuminate the targets directly through the objective lens we fabricated an epi-illumination system (ASKA Company, Katou, Japan) consisting of an LED array, a focusing lens, two objective lenses and a dichroic mirror (495 nm, FF495-Di03, Semrock, Inc., Rochester, NY, USA). The photostimulation was made by six blue LEDs $(460 \pm 10 \mathrm{~nm}$,
LXML-PB02, Philips Lumileds Lighting Co. San Jose, CA, USA) arrayed $2 \times 3$ (height $\times$ width) on a circuit board (p-ban.com Co., Tokyo, Japan) (Fig. 1c). Four green LEDs (520 \pm 15 nm, LXML-PM01-0100, Philips Lumileds Lighting Co.) were set at the corners for position adjustment. Each LED was analog-regulated using an LED driver (RCD-240.70, RECOM Power GmbH., Vienna, Austria; Supplementary Figure 1) and a computer with a homemade driving program $(\mathrm{C}++)$. The photostimulation of $\mathrm{L} 5$ was made by the 3 blue LEDs in the lower line that were turned on individually for $4 \mathrm{~ms}$ with a variable interval between 5 and $9 \mathrm{~s}$. The total number of photostimulations was set at 900 . The power density (irradiance) of each LED was directly measured under microscopy by a visible light-sensing thermopile (MIR-101Q, SSC Co., Ltd., Kuwana City, Japan) and was $2.0 \mathrm{~mW} / \mathrm{mm}^{2}$ at its focus.

\section{Imaging}

Although the cortical tissue was hard to visualize for individual neurons immediately after surgery, it had cleared up over the following 3 weeks, probably because of the suppression of inflammation and gliosis. One month after surgery, each awake mouse was restrained under the microscope (ECLIPSE FN1, Nikon Co., Tokyo, Japan) with $16 \times$ water-immersion objective lens (CFI75 LWD $16 \times \mathrm{W}$, Nikon: NA, 0.8 and WD, 3.0) using a head-holding device (MAG-1, Narishige). The microscope was focused on the region 500-750 $\mu \mathrm{m}$ under the cortical surface (layer 5, L5) of S1 through the microprism, and the images for R-CaMP2 were acquired using a two-photon microscopy system (A1R $\mathrm{MP}+$, Nikon) with a femtosecond-pulsed laser (Mai Tai ${ }^{\circledR}$ DeepSee $^{\mathrm{TM}}$, Spectra-Physics, Newport Co., Santa Clara, CA, USA) at $1000 \mathrm{~nm}$ for excitation, and a suppression filter $(629 \pm 56 \mathrm{~nm})$ for detection (Fig. 1d). The imaging field was $256 \times 512$ pixels $(375 \times 750 \mu \mathrm{m})$ at $50-150 \mu \mathrm{m}$ away from the surface of the microprism and sampled at $3.6 \mathrm{fps}$.

The R-CaMP2 images were analyzed using ImageJ and a homemade program $(\mathrm{C}++)$ according to the following procedures. (1) Two-dimensional movement of the image was corrected frame-by-frame. (2) Every single frame capturing the LED-dependent noise at the instance of photostimulation (4 ms), which contained the stray LED light and the R-CaMP2 fluorescent light excited by the LED with/without direct activation of neurons, was removed from the image stack. (3) Circular regions of interest (ROIs) were manually set on the neuron-like cell bodies and their average brightness values were sequentially measured as a function of time. (4) For every 10 frames (duration, 10/3.6 $\approx 2.8 \mathrm{~s}$ ) the standard deviation (SD) was calculated and its minimum was defined as noise $\mathrm{SD}\left(\mathrm{SD}_{0}\right)$. (5) The baseline fluorescence $\left(F_{\mathrm{b}}\right)$ of an ROI was updated with time in a series of records as the average fluorescence of 4 serial frames in which the 
A

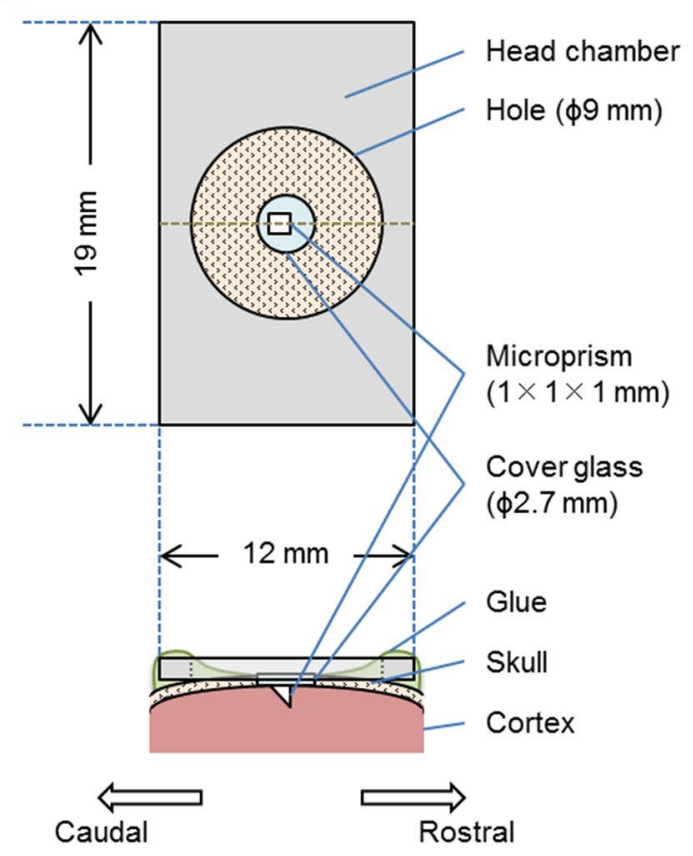

D

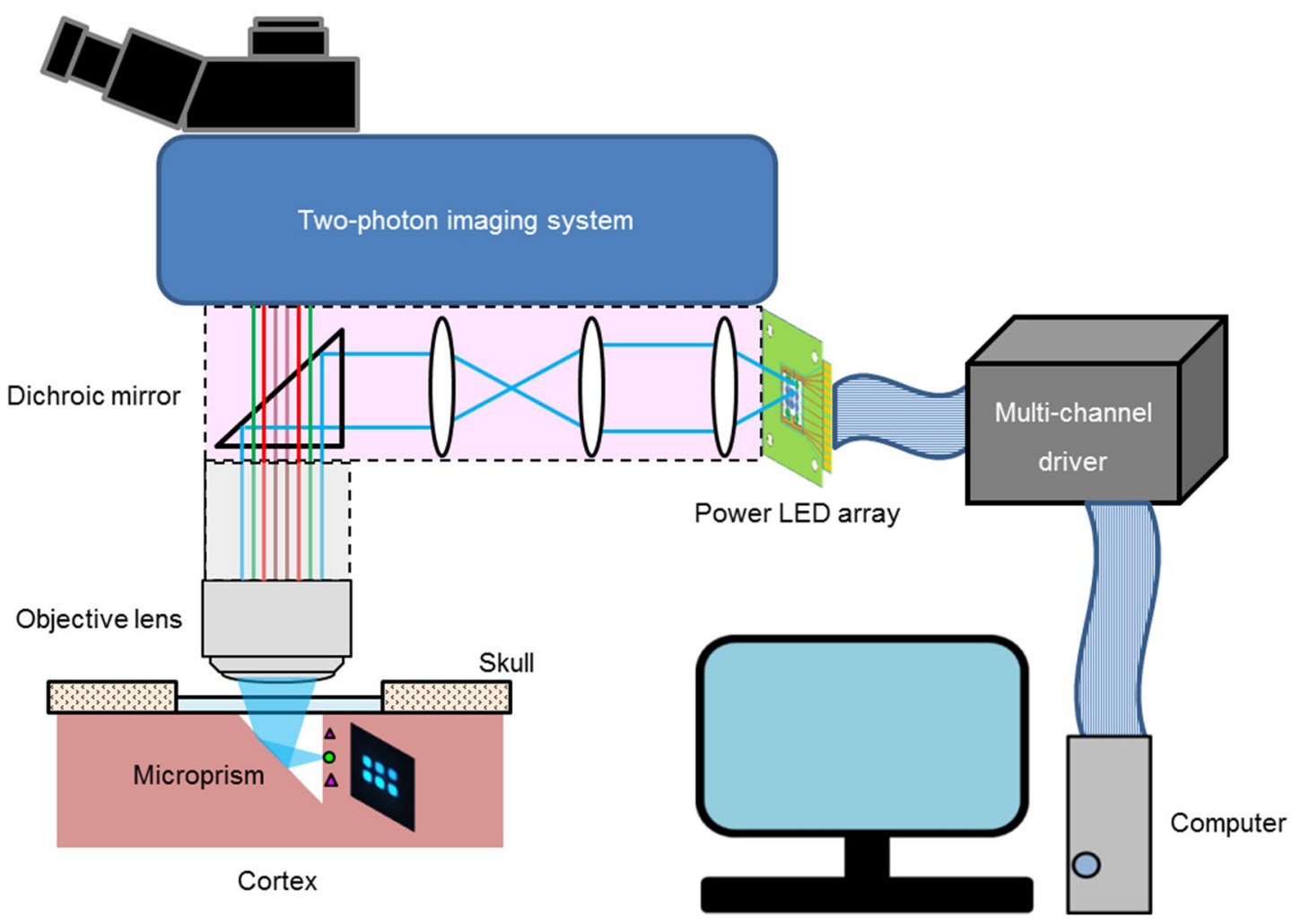

Fig. 1 The experimental setup. a Insertion and fixation of the microprism: the top view (top) and the side view (bottom). b Attachment of the head chamber on the mouse. $\mathbf{c}$ The array of power LEDs on the circuit board. d Schematic drawings of the all-optical system. The
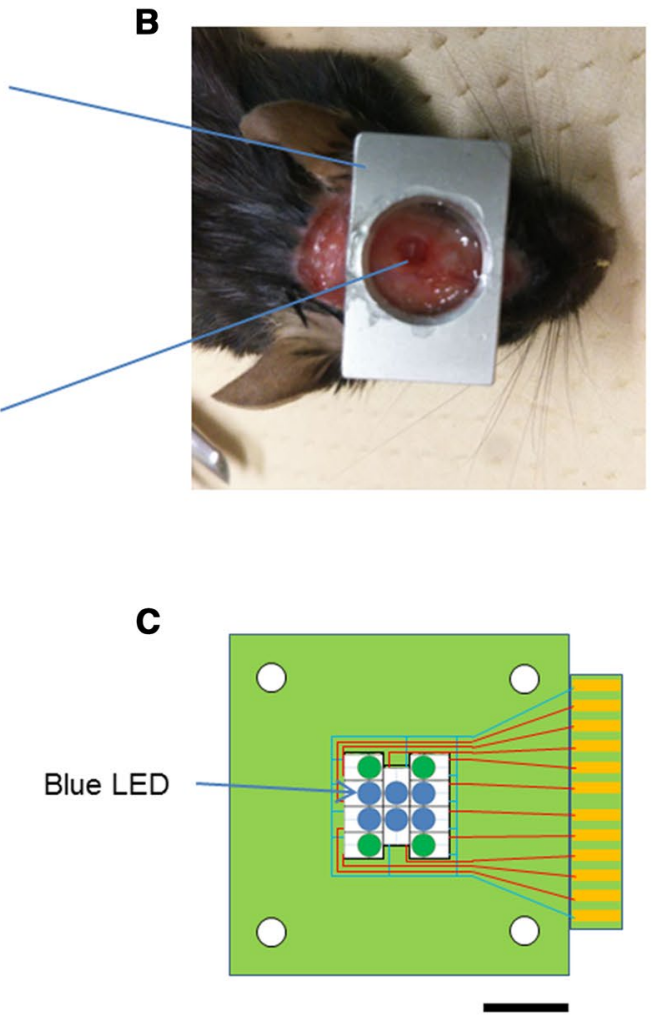

$10 \mathrm{~mm}$
LED light was focused in the cortical layer 5 (L5) directly through the dichroic mirror, the objective lens and the microprism with no interference from the two-photon imaging system 
range was within $\pm 3 \mathrm{SD}_{0}$. Otherwise, it was not updated. (6) The activated fluorescence $\left(F_{\mathrm{a}}\right)$ of the same ROI was defined as the value that exceeded $+6 \mathrm{SD}_{0}$ and its magnitude was expressed as $\Delta F / F=\left(F_{\mathrm{a}}-F_{\mathrm{b}}\right) / F_{\mathrm{b}}$. (7) The onset of each $\mathrm{Ca}^{2+}$ spike was determined according to the last baseline point just before the activated points.

\section{Statistics}

All data in the text, figures and tables are expressed as mean \pm SEM. The statistical evaluation was conducted using Fisher's exact test for the frequency, Mann-Whitney $U$ test for unpaired data, $t$-test for paired data, and one-way ANOVA with a Bonferroni post hoc test for data in order unless otherwise noted. The numbers of samples used for the statistics $(n)$ are shown in the figure legends. It was judged as statistically insignificant when $P>0.05$.

\section{Results}

In the present study, the adult mice were compelled to express channelrhodopsin and $\mathrm{Ca}^{2+}$ sensor in the somatosensory cortex (S1) using AAV. To photostimulate the local network, a chimeric channelrhodopsin between channelrhodopsin-1 (ChR1) and one of the Volvox-derived channelrhodopsins, C1V1 [17], was expressed in L5 under the CaMKII promotor. To record the network activity, the L5 neurons expressed R-CaMP2 [18], one of the RFP-derived $\mathrm{Ca}^{2+}$ sensors, non-selectively under the CAG promotor. The C1V1expressing neurons were identified immunohistochemically for the primary cultures from mouse cortex using anti-Venus antibodies. Among 111 Venus-positive neurons, 86 were obviously positive with CaMKII (Fig. 2a-c), whereas 4 were positive with GABA among 142 Venus-positive neurons (Fig. 2d-f). Thus, the probability of GABA co-expression was negligible relative to that of CaMKII (Fig. $2 \mathrm{~g}$ ).

The L5 neurons were visualized through a microprism inserted in the somatosensory cortex under two-photon microscopy (Fig. 3a, Supplementary Figure 2 and Supplementary Video 1). That is, neurons deep in the L5 were viewed from the side. On the other hand, the light from an array of blue LED chips was focused on the imaging plane through the objective lens and the microprism. Each LED chip illuminated one of the three circular targets (diameter, $\sim 100 \mu \mathrm{m}$ ), A, B or C, which were aligned in the L5 parallel to the cortical surface (Fig. 3a). The LED chips were turned on and off by one of the following modes of spatiotemporal pattern: the "single-mode", by which each of 3 targets was illuminated one by one in a random order and the "multi-mode", by which 2 of 3 targets were illuminated simultaneously or sequentially with an interval of either 2, 4 or $12 \mathrm{~ms}$. These two modes were scrambled in order while imaging the R-CaMP2 fluorescence (Fig. 3b).

\section{Response to the single-mode photostimulation}

A number of R-CaMP2-positive neurons were identified in an imaging plane set in the L5 of S1 (Fig. 3a). While transient increments of $\Delta F / F$, which were judged as $\mathrm{Ca}^{2+}$ spikes, occurred spontaneously under the awakened condition, they were often evoked immediately after photostimulation (Fig. 3b). For every L5 neuron, the $\mathrm{Ca}^{2+}$ spikes were aligned to the single-mode photostimulation at each of 3 targets, A, B and C, as shown by the sample raster plots in Fig. 3c-e. As shown in the histograms in Fig. 3f-h, the frequency of the $\mathrm{Ca}^{2+}$ spikes was significantly increased in the first scanning frame $(\sim 280 \mathrm{~ms})$ just after the single-mode photostimulation at target $\mathrm{B}$ $(P<0.05$, Fisher's exact test $)$, but not at either target A or $\mathrm{C}$. Therefore, this neuron was judged to be the target B-responsive neuron. A target-responsive neuron was thus defined as a ROI in which the frequency of $\mathrm{Ca}^{2+}$ spikes in response to the stimulation of the target was significantly larger than that in response to either of the other two targets. In summary, of 354 neurons in total ( $n=5$ animals), 224 were the target-responsive neurons $(65 \pm 9 \%, n=5)$, $121(32 \pm 7 \%, n=5)$ were non-responsive and $9(3 \pm 2 \%$, $n=5)$ showed significant decreases in the frequency of $\mathrm{Ca}^{2+}$ spikes after the single-mode photostimulation $(P<0.05$, Fisher's exact test).

The target A-, target B-, and target C-responsive neurons were respectively distributed close to the targets $\mathrm{A}, \mathrm{B}$ and $\mathrm{C}$, although a small number of neurons were responsive to multiple targets (Fig. $4 \mathrm{a}-\mathrm{c}$ ). Therefore, the excitatory influence of photostimulation, directly or indirectly, diminished with distance along a direction parallel to the cortical surface. To further analyze this, the imaging plane was divided into perpendicular stripes of $25 \mu \mathrm{m}$ width (Fig. 4d, top) and the response probability of neurons in a stripe was averaged for each target to derive the ensemble response probability $(p)$. As shown in Fig. 4d (bottom), $p$ was highest around at the center of the target and decreased with distance $(x)$. The relationship almost followed a single exponential function (Fig. 4d),

$p=p_{\max } e^{-\frac{x}{\lambda}}$,

where $\lambda$ is the length constant. The $\lambda$ values were similar among targets of photostimulation and among animals 

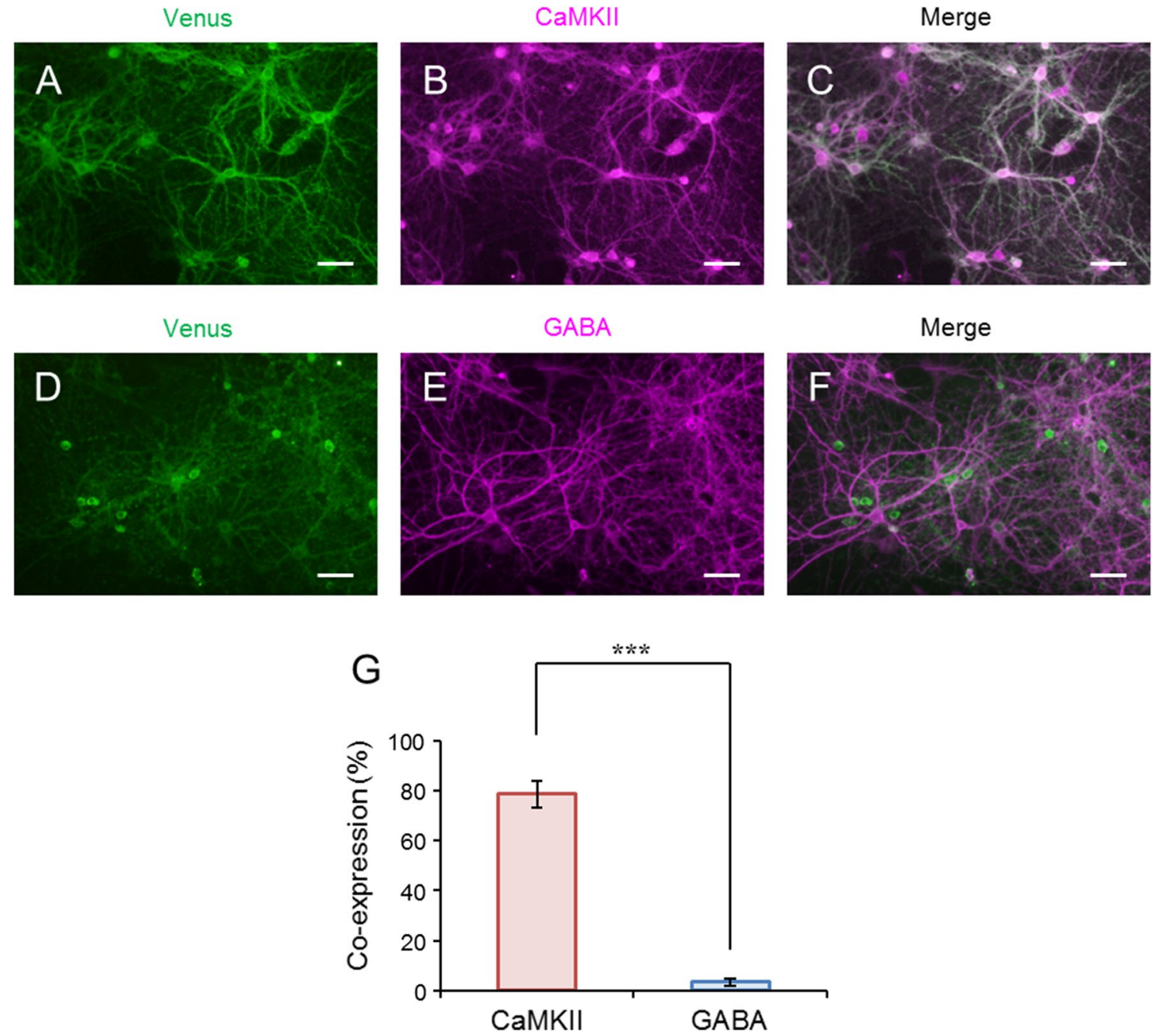

Fig. 2 Cortical expression of C1V1, a chimeric channelrhodopsin between channelrhodopsin-1 (ChR1) and one of the Volvox-derived channelrhodopsins. a-c Excitatory neurons in culture: C1V1-Venus immunoreactivity (a), CaMKII immunoreactivity (b) and the merge (c). d-f Inhibitory neurons in culture: C1V1-Venus immunoreactivity

in a range of $37-129 \mu \mathrm{m}(63 \pm 7 \mu \mathrm{m}, n=14$ targets, 5 animals).

\section{Response to the multi-mode photostimulation}

Would the simultaneous photostimulation of multiple targets enhance the responsiveness of a neuron? As shown in the example shown in Fig. 5a, the ensemble response probability of neurons in a perpendicular stripe to simultaneous photostimulation at targets $\mathrm{A}$ and $\mathrm{B}(\mathrm{A}+\mathrm{B})$ tended to be smaller than that to single-mode stimulation at target $\mathrm{A}$ or B. Therefore, the photostimulations at target A and B reciprocally inhibit each other. Similar reciprocal inhibition was present between photostimulations at targets B and C (Fig. 5b) or between photostimulations at targets A and C (d), GABA immunoreactivity (e) and the merge (f). g Co-expression of CaMKII and GABA in the Venus-positive neurons (summary of 10 visual fields). Scales, $50 \mu \mathrm{m}$ for all. $* * * P<0.0005$, Mann-Whitney $U$ test

(Fig. 5c). To evaluate the reciprocal inhibition quantitatively, neurons distributed in the region of 6 stripes around each target (range $\pm 75 \mu \mathrm{m}$ from the center) were selected and their ensemble response probabilities were compared between single-mode and multi-mode photostimulations (Fig. 5d-f). The response probability to the simultaneous photostimulation was indeed smaller than that to single-mode photostimulation with significant (or nearly significant) difference. In summary, the ensemble response probability to the simultaneous multi-mode photostimulation was $0.16 \pm 0.01$ ( $n=30$ cases, 5 animals), which was significantly smaller than that to the single-mode photostimulation, $0.25 \pm 0.02$ ( $n=15$ cases, 5 animals $)(P<0.05$, Mann-Whitney $U$ test $)$.

The magnitude of reciprocal inhibition was actually dependent on the interval between two photostimulations. 
A

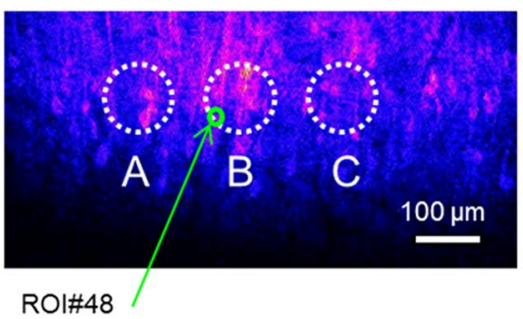

B

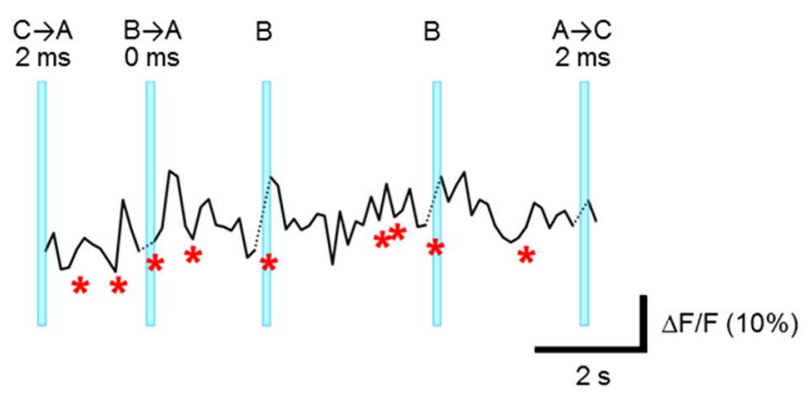

C

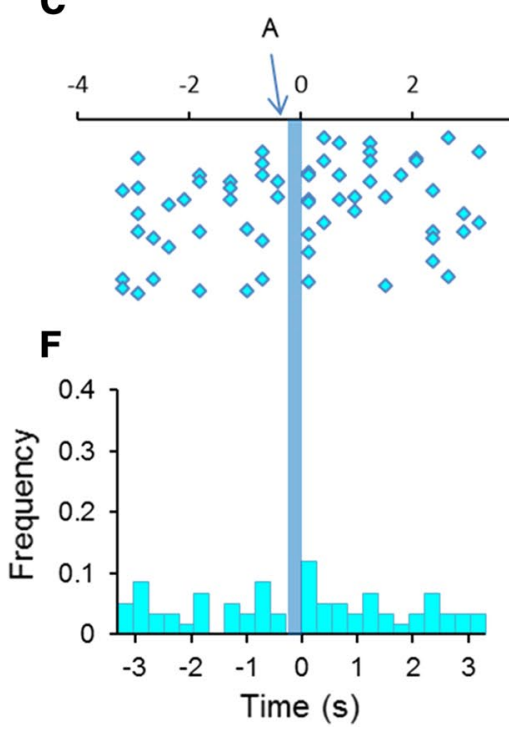

D

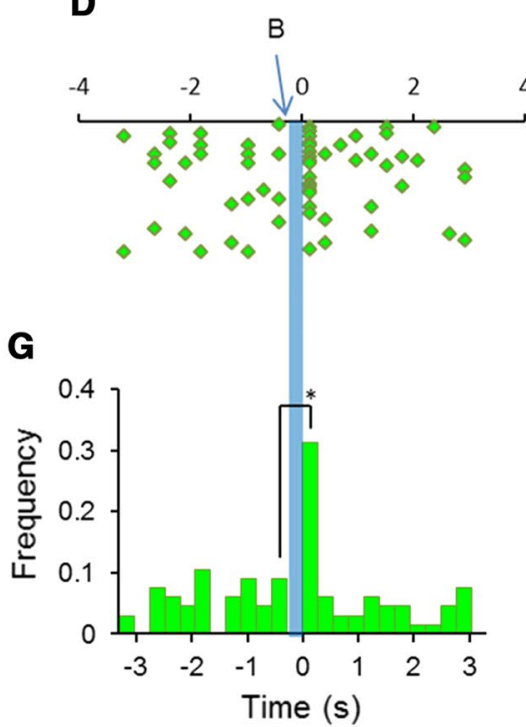

E

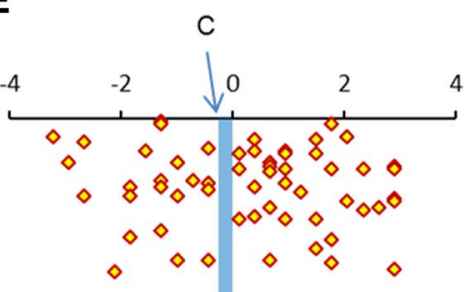

H

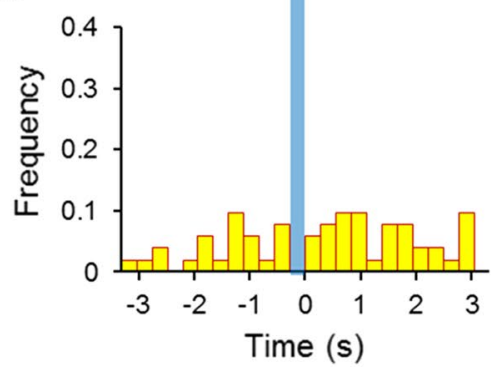

Fig. 3 Neuronal responses to the L5 photostimulation. a A typical R-CaMP2 fluorescence image at L5 through the prism. The targets of photostimulation, $\mathrm{A}, \mathrm{B}$, and $\mathrm{C}$ are overlaid (circles). One of the regions of interest (ROI) \#48 is encircled in green. b A sample record of $\mathrm{Ca}^{2+}$ signals ( $\triangle F / F$ of the R-CaMP2 fluorescence) at ROI \#48. The timing of each photostimulation is shown by a vertical bar (from left to right); the multi-mode photostimulation at $\mathrm{A}$ after $\mathrm{C}$ with $2 \mathrm{~ms}$ delay, the multi-mode photostimulation at A and B simultaneously,

To evaluate the effect of target $B$ photostimulation on the target A responsiveness (A/B), for example, the neurons distributed in the region of 6 stripes around the target were again selected, and the relative ensemble probabilities were compared for photostimulations at $\mathrm{B}$ before those at $\mathrm{A}$ by $12 \mathrm{~ms}(\mathrm{~A} / \mathrm{B},-12)$, by $4 \mathrm{~ms}(\mathrm{~A} / \mathrm{B},-4)$, by $2 \mathrm{~ms}(\mathrm{~A} / \mathrm{B}$, - 2), simultaneously at $A$ and $B(A / B, 0)$, at $B$ after $A$ by $2 \mathrm{~ms}(\mathrm{~A} / \mathrm{B}, 2)$, by $4 \mathrm{~ms}(\mathrm{~A} / \mathrm{B}, 4)$ and by $12 \mathrm{~ms}(\mathrm{~A} / \mathrm{B}, 12)$. As shown in Fig. 6a, the relative probability was dependent on the interval in any combination of photostimulations: minimal at $0 \mathrm{~ms}$ and almost negligible at $\pm 12 \mathrm{~ms}$. Similar multi-mode photostimulation was then subdivided into two classes: (1) multi-mode photostimulation of two close targets (A/B, B/A, B/C or $\mathrm{C} / \mathrm{B}$ ), and (2) that of two remote targets (A/C or $\mathrm{C} / \mathrm{A}$ ), and summarized for 5 animals (Fig. $6 \mathrm{~b}$ ). As there was no significant difference between these two classes at any interval $(P>0.2)$, the effects of the interval the single-mode photostimulation at $\mathrm{B}$, the single-mode photostimulation at $\mathrm{B}$ and the multi-mode photostimulation at $\mathrm{C}$ after $\mathrm{A}$ with $2 \mathrm{~ms}$ delay. Asterisk (red), the onset of the $\mathrm{Ca}^{2+}$ response. c-e Raster plots of the $\mathrm{Ca}^{2+}$ spikes from the ROI \#48 aligned to the single-mode photostimulation (dark bars) at A, B and C, respectively. f-h Histograms of the time-dependent frequency of $\mathrm{Ca}^{2+}$ spikes in relation to the single-mode photostimulation (dark bars) at A, B and C, respectively. ${ }^{*} P<0.05$, Fisher's exact test (color figure online)

were evaluated for all pairs ( $n=30,5$ animals) and found to be asymmetrical. For example, the relative probability at -4 and -2 was respectively smaller than that at 4 and 2 with significant difference $(P<0.05$ and $<0.01)$. Although the differences between -12 vs -4 and 0 vs 2 were significant $(P<0.01)$, the differences between -2 vs 0 and 4 vs 12 were insignificant $(P>0.05)$.

\section{Discussion}

\section{All-optical approach}

The neuronal network in the brain can be regarded as a kind of multi-dimensional transfer function of time and has been investigated through analyzing the input-output relationship. The optical imaging of neuronal activity using genetically 
Fig. 4 L5 neuron activation by single-mode photostimulation. a Distribution of the target A-responsive neurons. The same sample is shown in Fig. 3. b Distribution of the target B-responsive neurons. c Distribution of the target C-responsive neurons. $\mathbf{d}$ The ensemble response probability of neurons as a function of the distance along a direction parallel to the cortical surface; the responsiveness to A-photostimulation (light blue columns), B-photostimulation (light green columns) and C-photostimulation (yellow columns), respectively. e The ensemble response probability $(p)$ as a function of distance $(x)$ from the center of each target; A-photostimulation (light blue diamonds), B-photostimulation (light green triangles) and C-photostimulation (yellow circles). Each line is the leastsquares fitting curve of a single exponential function (color figure online)
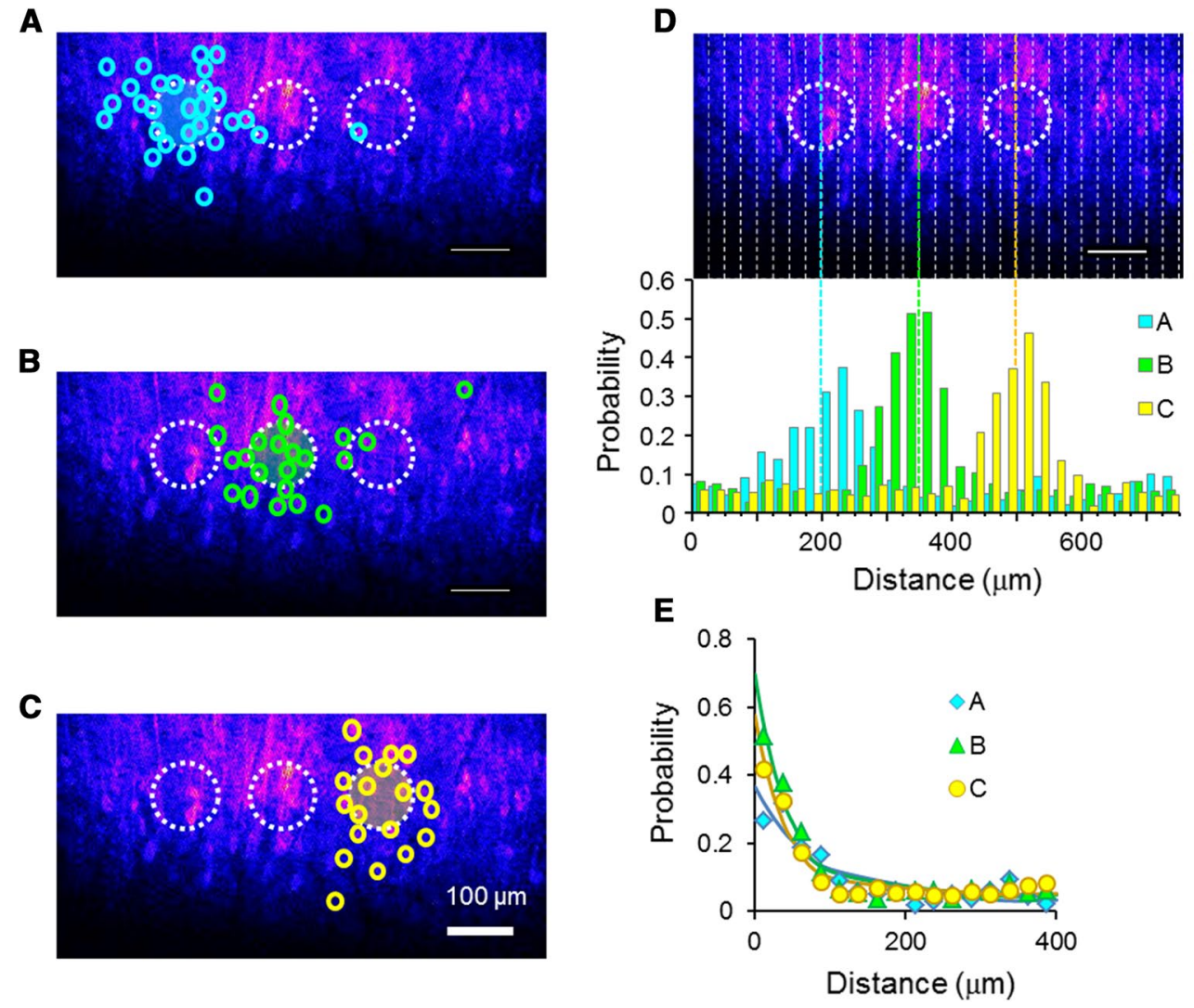

encoded $\mathrm{Ca}^{2+}$ indicators or voltage sensors would be advantageous over other methods in the high spatiotemporal resolutions discriminating individual neurons [19-22]. As an artificial input, the optical stimulation using optogenetics has advantages over other methods such as electrical stimulation in its high spatiotemporal precision [23-28]. However, the power of visible light is massively attenuated with distance because of scattering and absorption by the brain tissue [25, 29]. On the other hand, a strong light would actuate neurons non-selectively in its path. To solve this, two-photon optics has been applied for both photostimulation of target neurons and imaging of neuronal activity in the mouse brain in vivo: L2/3 of somatosensory cortex [30] and visual cortex [31]. Although the conventional diffraction-limited two-photon laser system has been rather ineffective for exciting neurons due to the small single-channel conductance of channelrhodopsins (40 fS $\sim 1.1 \mathrm{pS}$ for ChR2 and ChR $1 / 2$ chimera) [32-34] and insufficient two-photon absorption volume $\left(\sim 2-5 \mu \mathrm{m}^{3}\right)$ [35], attempts have been made to apply the high energy of a laser over the cell of interest for a short duration [28, 36-38].

Recently, deep cortical layers have been imaged by combining a microscope with a microprism inserted in the in vivo brain [39]. As a result, the microscopic light is expected to be focused on the vertical visual field directly without mediating tissue while collecting the sample light with minimal diffraction. In the present study, the blue LED light was directly focused in the L5 of mouse cortex through a microprism to excite the neurons that expressed C1V1. Our approach has several advantages and disadvantages. It can excite a homogeneous group of neurons at once because of the localization of a light path within the layer, although is difficult to differentiate individual cells for excitation because of the low spatial resolution of a single photon beam. The on-off timing of irradiation can be precisely regulated for multiple targets when each LED is individually regulated. It can be combined with any microscopic system with minimal modification. However, the possibility should be kept in mind that the two-photon imaging could depolarize the membrane potential of a $\mathrm{C} 1 \mathrm{~V} 1$-expressing neuron with increased excitability. Although some of the cortical connections were disrupted or disorganized by the chronic insertion of a microprism, the basic properties of the local circuit should remain intact [39]. Since the LED pulse was short in duration $(4 \mathrm{~ms})$, it would evoke only a few action potentials in neurons that expressed C1V1 $[17,40]$. On the other hand, the $\mathrm{Ca}^{2+}$ spike is assumed to be generated by a burst of action potentials because of the response characteristics of R-CaMP2 [18]. Although we made a ROI on a neuron-like cell body, the measured fluorescence may have been contaminated with that from the neighboring neuropil. This approach could be improved by increasing the resolution of 
Fig. 5 L5 neuron activation by multi-mode photostimulation. a The ensemble response probability of neurons to the simultaneous photostimulation of targets $\mathrm{A}$ and $\mathrm{B}(\mathrm{A}+\mathrm{B}$, dark blue columns) as a function of the distance along a direction parallel to the cortical surface, where the background columns are the ensemble response probability to the single-mode photostimulation at $\mathrm{A}$ (light blue) and at $\mathrm{B}$ (light green). b Similar to A, but of targets $\mathrm{B}$ and $\mathrm{C}(\mathrm{B}+\mathrm{C}$, dark green columns). c Similar to A, but of targets $\mathrm{A}$ and $\mathrm{C}(\mathrm{A}+\mathrm{C}$, brown columns). d Comparison of the average response probability of the region $\pm 75 \mu \mathrm{m}$ from the center of targets $\mathrm{A}$ and $\mathrm{B}$ (double-headed arrows shown in A). The symbols with lines indicate the individual data whereas each column with bars is mean \pm SEM (A: $n=5, \mathrm{~B}: n=5, \mathrm{~A}+\mathrm{B}: n=10)$. e Similar to D, but of targets B and C. f Similar to D, but of targets $\mathrm{A}$ and $\mathrm{C} . * P<0.05$, $* * * P<0.0005$, paired $t$-test (color figure online)

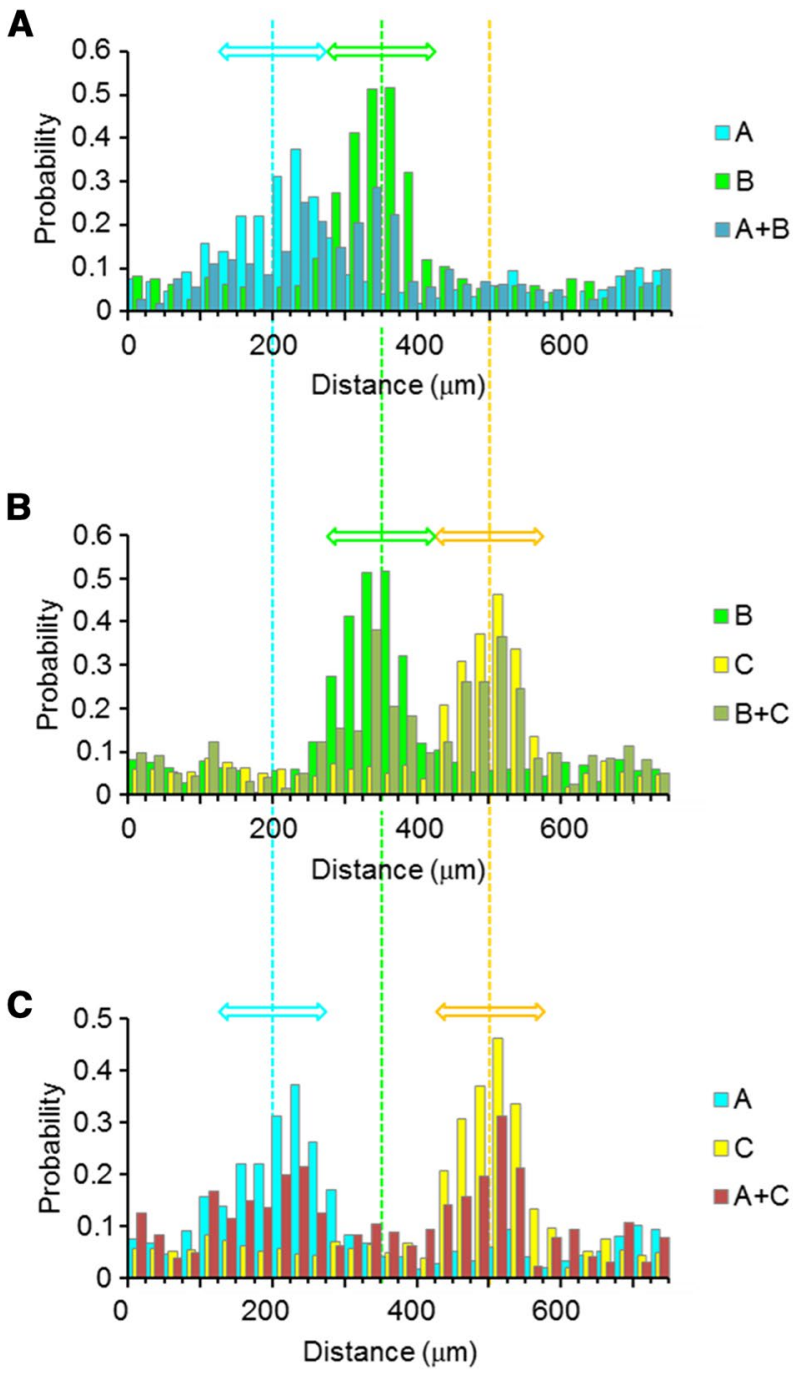

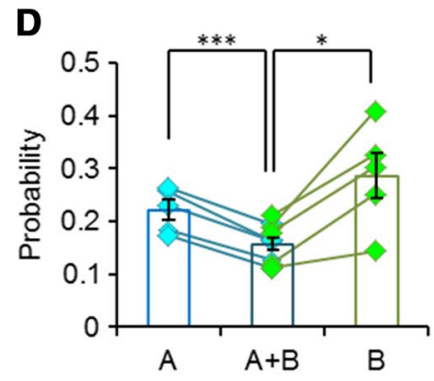
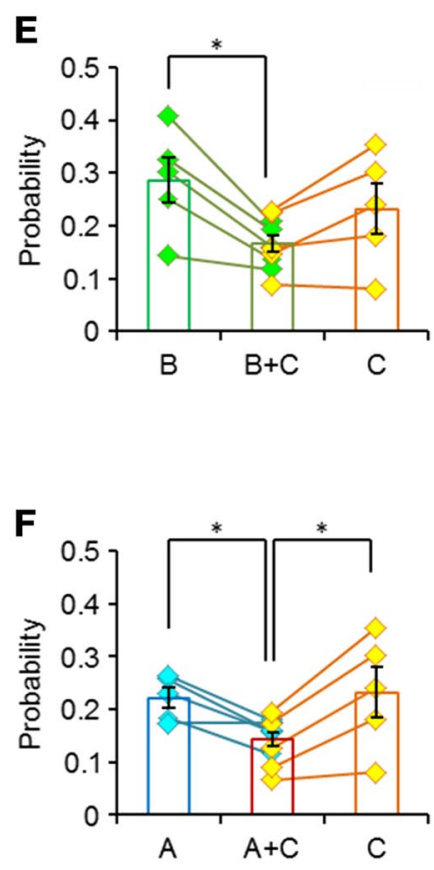

the irradiating apparatus using a digital micromirror device (DMD), liquid crystal display, and liquid crystal on a silicon/ spatial light modulator (LCoS/SLM) [41-44]. For example, point irradiation of blue light on the background of yellow/ red light would excite individual cells that express stepfunction opsins (SFO) in the membrane with high precision and efficiency [45-47].

\section{Functional emergence of column-like architecture}

The present study is the first all-optical approach to investigate the input-output characteristics of the deep cortical layer circuitry in an awake mouse. The excitability was spread around the blue-light irradiated region, but the horizontal propagation was limited within a certain distance $(\lambda<130 \mu \mathrm{m}$ from the center of the spot) and within a single frame of imaging $(<0.3 \mathrm{~s})$. Therefore, a column-like excitatory cluster $100-300 \mu \mathrm{m}$ in diameter appeared to emerge transiently in response to an input into L5. Some neurons in the cluster may have expressed C1V1 to be excited directly by the blue light irradiation on their soma, dendrites and/ or axons, and others should have been excited indirectly through synapses. In addition, a C1V1-expressing neuron could also be synaptically activated to generate $\mathrm{Ca}^{2+}$ spikes even if the light-dependent depolarization of its membrane potential would be subthreshold for generating action potentials. Nevertheless, the column-like cluster, which consists of the directly and indirectly activated neurons, functionally emerged with regional photostimulation of L5 with a spatiotemporal restriction. The size of the column-like cluster is consistent with that of functional columns described previously [3-5, 48], and that predicted from the receptive field of individual neurons [13]. It is possible that this column-like excitatory cluster consists of smaller substructures, such as an L5 microcolumn/lattice $[49,50]$ and cortical microcircuit [51-54]. The functional organization of these substructures should be revealed in the future by differential optogenetic excitation of neuronal subtypes $[55,56]$ that have been classified by morphology, projection targets, electrophysiological properties, local excitatory connectivity and long-range 


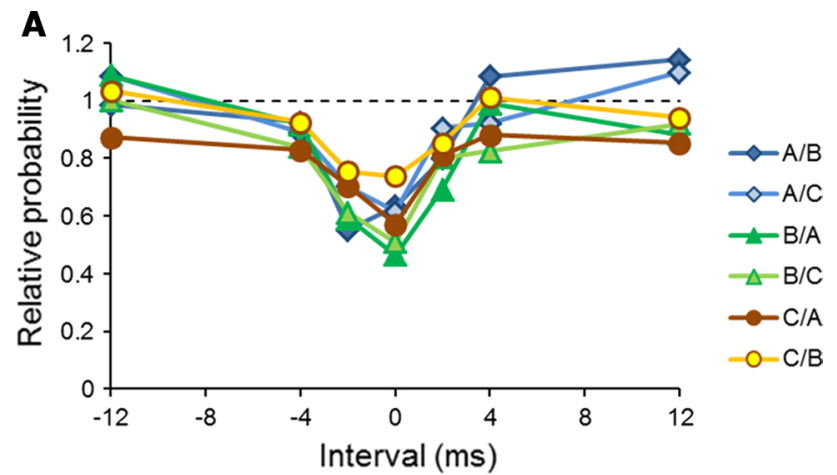

B
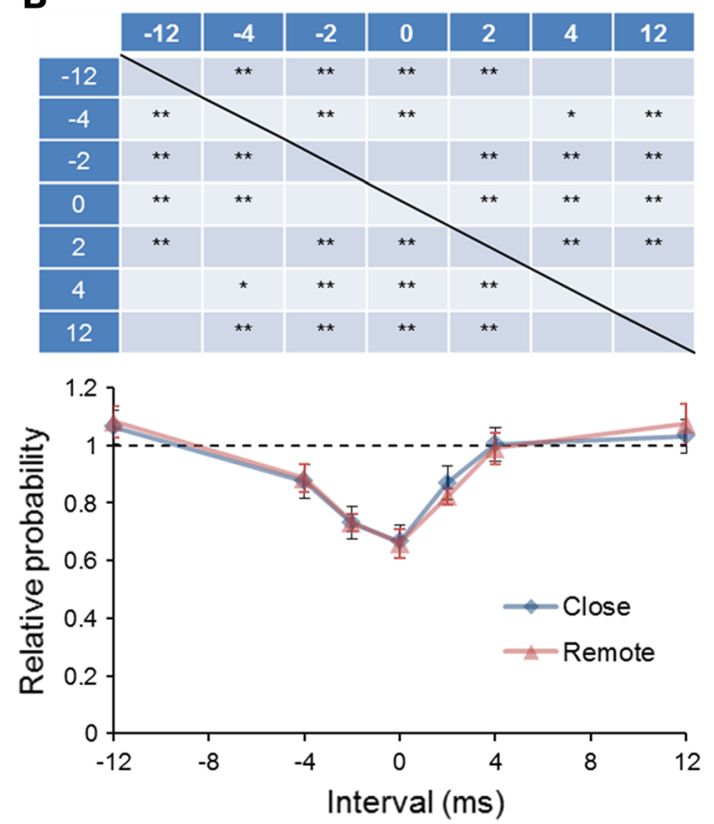

Fig. 6 Time-lag dependency of the reciprocal inhibition. a The relative probability of multi-mode photostimulation to the response of a single-mode photostimulation as a function of the time-lag interval between additional photostimulation: minus when the addition is a precedent, zero when the addition is simultaneous, and plus when the addition is succeeding. Data from the sample shown in Fig. 5. $X / Y$ : relative response to the photostimulation at $X(\mathrm{~A}, \mathrm{~B}$ or $\mathrm{C})$ with additional photostimulation at $\mathrm{Y}(\mathrm{A}, \mathrm{B}$ or $\mathrm{C})$. b Similar to A, but the summary (mean $\pm \mathrm{SEM}$ ) of the relative probability for two close targets $(\mathrm{A} / \mathrm{B}, \mathrm{B} / \mathrm{A}, \mathrm{B} / \mathrm{C}$ and $\mathrm{C} / \mathrm{B}$, diamonds, $n=20,5$ animals $)$ and that of two remote targets (A/C and C/A, triangles, $n=10,5$ animals). ${ }^{*} P<0.05, * * P<0.01$, one-way ANOVA with a Bonferroni post hoc test $(\mathrm{A} / \mathrm{B}, \mathrm{B} / \mathrm{A}, \mathrm{B} / \mathrm{C}, \mathrm{C} / \mathrm{B}, \mathrm{A} / \mathrm{C}$ and $\mathrm{C} / \mathrm{A}, n=30,5$ animals)

inputs [57]: the corticocallosally projecting slender-tufted (L5A) and subcortical targeting thick tufted (L5B) pyramidal neurons [58-62]; the corticopontine (CPn) and crossed corticostriatal (CCS) neurons [63].

\section{Reciprocal inhibition}

The neocortical circuit is composed of excitatory principal neurons and inhibitory interneurons. As a result, the excitation of L5 pyramidal neurons should inhibit other neurons and vice versa through inhibitory interneurons in the L5 and/or via other layers [57]. It has been postulated that the L5 output signal should be sculptured by the excitatory-inhibitory balance $[8,13]$. This notion was confirmed by the present study showing that the columnlike excitatory clusters inhibited each other reciprocally with a minimal number of the synaptic relays because the inhibition was maximal when neurons in another target were excited before $0-2 \mathrm{~ms}$. However, there was a negligible possibility that the inhibitory neurons were directly activated by light because of the negligible expression of C1V1 under the CaMKII promotor using AAV. The inhibition propagated horizontally without obvious attenuation: the inhibition between adjacent targets (distance, $\sim 150 \mu \mathrm{m}$ ) was similar to that between remote targets (distance, $\sim 300 \mu \mathrm{m}$ ). These facts are consistent with that some types of cortical interneurons such as the parvalbumin (PV)-expressing basket cells and chandelier cells have long-range connections with L5 pyramidal neurons [64, 65]. These neurons as well as other types of interneurons, such as the somatostatin (SOM)-expressing Martinotti cells [66, 67], may be involved in the reciprocal inhibition. Once an input is made regionally in the L5, the columnlike excitatory cluster should be self-organized through local excitatory connections among L5 pyramidal neurons and sculptured spatially and temporally by the long-range reciprocal inhibitory connections. This could generate a synchronous output from a region of L5 with simultaneous enhancement of the signal-to-noise ratio by the silencing of neighboring regions $[6,68,69]$. It is hypothesized that the long-range inhibitory signals also sculpture other layers such as layer $2 / 3$ to help the functional emergence of a column-like architecture through the layers in a manner dependent on the L5 inputs [70]. In the primary sensory cortex, the thalamic inputs would excite L5 pyramidal neurons directly or indirectly through activation of layer $4[3,13,56]$. The regional excitation of L5 would, in turn, conduct the cortical circuitry to generate a column-like functional architecture. This hypothesis could be tested in the future through an all-optical approach in combination with a multilayer imaging system [39].

Acknowledgements We thank K. Fukunaga for the generous gift of rabbit pan CaMKII antiserum and B. Bell for language assistance. This work was supported by a Grant-in-Aid for Scientific Research (No. 25250001 to HY), a Grant-in-Aid for Scientific Research on Innovative Areas (Adaptive Circuit Shift: No. 15H01413 to HY; Comprehensive Brain Science Network; Platforms for Advanced Technologies and Research Resources: No. 16H06276 to HB) of the Ministry of Education, Culture, Sports, Science and Technology (MEXT) of Japan: http://www.jsps.go.jp/english/e-grants/grants01.html as well as JST, Strategic International Collaborative Research Program, SICORP (to HY): http://www.jst.go.jp/inter/english/sicorp/index.html and CREST (JPMJCR1656 to AY). 
Author contributions KK contributed to conceiving, designing and performing the experiments. $\mathrm{KK}$ and $\mathrm{HY}$ contributed to data analysis. $\mathrm{MI}, \mathrm{SC}, \mathrm{HB}, \mathrm{AY}$ and TI contributed by providing reagents, materials, and analysis tools. KK and HY contributed to data interpretation and manuscript writing. All authors approved the final version of the manuscript.

\section{Compliance with ethical standards}

Conflict of interest The authors declare that they have no conflicts of interest.

Statement on the welfare of animals All applicable international, national, and/or institutional guidelines for the care and use of animals were followed. All procedures performed in studies involving animals were in accordance with the ethical standards of the institution or practice at which the studies were conducted. This article does not contain any studies with human participants performed by any of the authors.

\section{References}

1. Harris KD, Mrsic-Flogel TD (2013) Cortical connectivity and sensory coding. Nature 503:51-58. https://doi.org/10.1038/natur e12654

2. Zeng H, Sanes JR (2017) Neuronal cell-type classification: challenges, opportunities and the path forward. Nat Rev Neurosci 18:530-546. https://doi.org/10.1038/nrn.2017.85

3. Lübke J, Feldmeyer D (2007) Excitatory signal flow and connectivity in a cortical column: focus on barrel cortex. Brain Struct Funct. 212:3-17. https://doi.org/10.1007/s00429-007-0144-2

4. Hubel DH, Wiesel TN (1962) Receptive fields, binocular interaction and functional architecture in the cat's visual cortex. J Physiol 160:106-154. https://doi.org/10.1113/jphysiol.1962.sp006837

5. Hubel DH, Wiesel TN (1977) Ferrier lecture. Functional architecture of macaque monkey visual cortex. Proc R Soc Lond B Biol Sci 198:1-59. https://doi.org/10.1098/rspb.1977.0085

6. Miller KD, Keller JB, Stryker MP (1989) Ocular dominance column development: analysis and simulation. Science 245:605-615. https://doi.org/10.1126/science. 2762813

7. Hensch TK, Stryker MP (2004) Columnar architecture sculpted by GABA circuits in developing cat visual cortex. Science 303:16781681. https://doi.org/10.1126/science.1091031

8. Isaacson JS, Scanziani M (2011) How inhibition shapes cortical activity. Neuron 72:231-243. https://doi.org/10.1016/j.neuro n.2011.09.027

9. Lee SH, Kwan AC, Zhang S, Phoumthipphavong V, Flannery JG, Masmanidis SC, Taniguchi H, Huang ZJ, Zhang F, Boyden ES, Deisseroth K, Dan Y (2012) Activation of specific interneurons improves V1 feature selectivity and visual perception. Nature 488:379-383. https://doi.org/10.1038/nature11312

10. Kim K, Kim JH, Song YH, Lee SH (2017) Functional dissection of inhibitory microcircuits in the visual cortex. Neurosci Res 116:70-76. https://doi.org/10.1016/j.neures.2016.09.003

11. Markram H, Toledo-Rodriguez M, Wang Y, Gupta A, Silberberg $\mathrm{G}, \mathrm{Wu} \mathrm{C}$ (2004) Interneurons of the neocortical inhibitory system. Nat Rev Neurosci 5:793-807. https://doi.org/10.1038/nrn1519

12. Kubota Y, Karube F, Nomura M, Kawaguchi Y (2016) The diversity of cortical inhibitory synapses. Front Neural Circuits. 10:27. https://doi.org/10.3389/fncir.2016.00027

13. Markram H, Muller E, Ramaswamy S, Reimann MW, Abdellah M, Sanchez CA, Ailamaki A, Alonso-Nanclares L, Antille N, Arsever S, Kahou GA, Berger TK, Bilgili A, Buncic N,
Chalimourda A, Chindemi G, Courcol JD, Delalondre F, Delattre V, Druckmann S, Dumusc R, Dynes J, Eilemann S, Gal E, Gevaert ME, Ghobril JP, Gidon A, Graham JW, Gupta A, Haenel V, Hay E, Heinis T, Hernando JB, Hines M, Kanari L, Keller D, Kenyon J, Khazen G, Kim Y, King JG, Kisvarday Z, Kumbhar P, Lasserre S, Le Bé JV, Magalhães BR, MerchánPérez A, Meystre J, Morrice BR, Muller J, Muñoz-Céspedes A, Muralidhar S, Muthurasa K, Nachbaur D, Newton TH, Nolte M, Ovcharenko A, Palacios J, Pastor L, Perin R, Ranjan R, Riachi I, Rodríguez JR, Riquelme JL, Rössert C, Sfyrakis K, Shi Y, Shillcock JC, Silberberg G, Silva R, Tauheed F, Telefont M, Toledo-Rodriguez M, Tränkler T, Van Geit W, Díaz JV, Walker R, Wang Y, Zaninetta SM, DeFelipe J, Hill SL, Segev I, Schürmann F (2015) Reconstruction and simulation of neocortical microcircuitry. Cell 163:456-492. https://doi.org/10.1016/j. cell.2015.09.029

14. Reid RC (2012) From functional architecture to functional connectomics. Neuron 75:209-217. https://doi.org/10.1016/j.neuro n.2012.06.031

15. Inutsuka A, Yamashita A, Chowdhury S, Nakai J, Ohkura M, Taguchi T, Yamanaka A (2016) The integrative role of orexin/ hypocretin neurons in nociceptive perception and analgesic regulation. Sci Rep 6:29480. https://doi.org/10.1038/srep29480

16. Kawashima T, Kitamura K, Suzuki K, Nonaka M, Kamijo S, Takemoto-Kimura S, Kano M, Okuno H, Ohki K, Bito H (2013) Functional labeling of neurons and their projections using the synthetic activity-dependent promoter E-SARE. Nat Methods 10:889-895. https://doi.org/10.1038/nmeth.2559

17. Yizhar O, Fenno LE, Prigge M, Schneider F, Davidson TJ, O'Shea DJ, Sohal VS, Goshen I, Finkelstein J, Paz JT, Stehfest K, Fudim R, Ramakrishnan C, Huguenard JR, Hegemann P, Deisseroth K (2011) Neocortical excitation/inhibition balance in information processing and social dysfunction. Nature 477:171-178. https://doi.org/10.1038/nature 10360

18. Inoue $\mathrm{M}$, Takeuchi A, Horigane S, Ohkura M, Gengyo-Ando K, Fujii H, Kamijo S, Takemoto-Kimura S, Kano M, Nakai J, Kitamura K, Bito H (2015) Rational design of a high-affinity, fast, red calcium indicator R-CaMP2. Nat Methods 12:64-70. https://doi.org/10.1038/nmeth.3185

19. Nagai T, Horikawa K, Saito K, Matsuda T (2014) Genetically encoded $\mathrm{Ca}^{2+}$ indicators; expanded affinity range, color hue and compatibility with optogenetics. Front Mol Neurosci 7:90. https ://doi.org/10.3389/fnmol.2014.00090

20. Antic SD, Empson RM, Knöpfel T (2016) Voltage imaging to understand connections and functions of neuronal circuits. $J$ Neurophysiol 116:135-152. https://doi.org/10.1152/jn.00226 .2016

21. Storace D, Sepehri Rad M, Kang B, Cohen LB, Hughes T, Baker BJ (2016) Toward better genetically encoded sensors of membrane potential. Trends Neurosci 39:277-289. https://doi.org/10.1016/j. tins.2016.02.005

22. Sepehri Rad M, Choi Y, Cohen LB, Baker BJ, Zhong S, Storace DA, Braubach OR (2017) Voltage and calcium imaging of brain activity. Biophys J 113:2160-2167. https://doi.org/10.1016/j. bpj.2017.09.040

23. Boyden ES, Zhang F, Bamberg E, Nagel G, Deisseroth K (2005) Millisecond-timescale, genetically targeted optical control of neural activity. Nat Neurosci 8:1263-1268. https://doi.org/10.1038/ nn 1525

24. Ishizuka T, Kakuda M, Araki R, Yawo H (2006) Kinetic evaluation of photosensitivity in genetically engineered neurons expressing green algae light-gated channels. Neurosci Res 54:85-94. https://doi.org/10.1016/j.neures.2005.10.009

25. Yizhar O, Fenno LE, Davidson TJ, Mogri M, Deisseroth K (2011) Optogenetics in neural systems. Neuron 71:9-34. https://doi. org/10.1016/j.neuron.2011.06.004 
26. Yawo H, Asano T, Sakai S, Ishizuka T (2013) Optogenetic manipulation of neural and non-neural functions. Dev Growth Differ 55:474-490. https://doi.org/10.1111/dgd.12053

27. Oertner TG, Helmchen F, de Lecea L, Beck H, Konnerth A, Kaupp B, Knöpfel T, Yawo H, Häusser M (2013) Optogenetic analysis of mammalian neural circuits. In: Hegemann P, Sigrist S (eds) Optogenetics, Dahlem Workshop Reports. De Gruyter, Berlin, pp 109-126

28. Yawo H, Egawa R, Hososhima S, Wen L (2015) General description: future prospects of optogenetics. In: Kandori H, Yawo H, Koizumi A (eds) Optogenetics: light-sensing proteins and their applications. Springer, Tokyo, pp 111-132

29. Aravanis AM, Wang LP, Zhang F, Meltzer LA, Mogri MZ, Schneider MB, Deisseroth K (2007) An optical neural interface: in vivo control of rodent motor cortex with integrated fiberoptic and optogenetic technology. J Neural Eng 4:S143-S156. https:// doi.org/10.1088/1741-2560/4/3/S02

30. Packer AM, Russell LE, Dalgleish HW, Häusser M (2015) Simultaneous all-optical manipulation and recording of neural circuit activity with cellular resolution in vivo. Nat Methods 12:140-146. https://doi.org/10.1038/nmeth.3217

31. Carrillo-Reid L, Yang W, Bando Y, Peterka DS, Yuste R (2016) Imprinting and recalling cortical ensembles. Science 353:691694. https://doi.org/10.1126/science.aaf7560

32. Nagel G, Szellas T, Huhn W, Kateriya S, Adeishvili N, Berthold P, Ollig D, Hegemann P, Bamberg E (2003) Channelrhodopsin-2, a directly light-gated cation-selective membrane channel. Proc Natl Acad Sci USA 100:13940-13945. https://doi.org/10.1073/ pnas. 1936192100

33. Feldbauer K, Zimmermann D, Pintschovius V, Spitz J, Bamann C, Bamberg E (2009) Channelrhodopsin-2 is a leaky proton pump. Proc Natl Acad Sci U S A. 106:12317-12322. https://doi. org/10.1073/pnas.0905852106

34. Lin JY, Lin MZ, Steinbach P, Tsien RY (2009) Characterization of engineered channelrhodopsin variants with improved properties and kinetics. Biophys J 96:1803-1814. https://doi.org/10.1016/j. bpj.2008.11.034

35. Papagiakoumou E, Anselmi F, Bègue A, de Sars V, Glückstad J, Isacoff EY, Emiliani V (2010) Scanless two-photon excitation of channelrhodopsin-2. Nat Methods 7:848-854. https://doi. org/10.1038/nmeth.1505

36. Peron S, Svoboda K (2011) From cudgel to scalpel: toward precise neural control with optogenetics. Nat Methods 8:30-34. https:// doi.org/10.1038/nmeth.f.325

37. Chaigneau E, Ronzitti E, Gajowa MA, Soler-Llavina GJ, Tanese D, Brureau AY, Papagiakoumou E, Zeng H, Emiliani V (2016) Two-photon holographic stimulation of ReaChR. Front Cell Neurosci 10:234. https://doi.org/10.3389/fncel.2016.00234

38. Ronzitti E, Conti R, Zampini V, Tanese D, Foust AJ, Klapoetke N, Boyden ES, Papagiakoumou E, Emiliani V (2017) Submillisecond optogenetic control of neuronal firing with two-photon holographic photoactivation of Chronos. J Neurosci 37:10679-10689. https://doi.org/10.1523/JNEUROSCI.1246-17.2017

39. Andermann ML, Gilfoy NB, Goldey GJ, Sachdev RN, Wölfel M, McCormick DA, Reid RC, Levene MJ (2013) Chronic cellular imaging of entire cortical columns in awake mice using microprisms. Neuron 80:900-913. https://doi.org/10.1016/j.neuro n.2013.07.052

40. Hososhima S, Yuasa H, Ishizuka T, Hoque MR, Yamashita T, Yamanaka A, Sugano E, Tomita H, Yawo H (2015) Near-infrared (NIR) up-conversion optogenetics. Sci Rep 5:16533. https://doi. org/10.1038/srep16533

41. Sakai S, Ueno K, Ishizuka T, Yawo H (2013) Parallel and patterned optogenetic manipulation of neurons in the brain slice using a DMD-based projector. Neurosci Res 75:59-64. https:// doi.org/10.1016/j.neures.2012.03.009
42. Favre-Bulle IA, Preece D, Nieminen TA, Heap LA, Scott EK, Rubinsztein-Dunlop H (2015) Scattering of sculpted light in intact brain tissue, with implications for optogenetics. Sci Rep 5:11501. https://doi.org/10.1038/srep11501

43. Roy A, Osik JJ, Ritter NJ, Wang S, Shaw JT, Fiser J, Van Hooser SD (2016) Optogenetic spatial and temporal control of cortical circuits on a columnar scale. J Neurophysiol 115:1043-1062. https://doi.org/10.1152/jn.00960.2015

44. Zhao ZD, Yang WZ, Gao C, Fu X, Zhang W, Zhou Q, Chen W, Ni X, Lin JK, Yang J, Xu XH, Shen WL (2017) A hypothalamic circuit that controls body temperature. Proc Natl Acad Sci USA 114:2042-2047. https://doi.org/10.1073/pnas.1616255114

45. Berndt A, Yizhar O, Gunaydin LA, Hegemann P, Deisseroth K (2009) Bi-stable neural state switches. Nat Neurosci 12:229234. https://doi.org/10.1038/nn.2247

46. Bamann C, Gueta R, Kleinlogel S, Nagel G, Bamberg E (2010) Structural guidance of the photocycle of channelrhodopsin-2 by an interhelical hydrogen bond. Biochemistry 49:267-278. https ://doi.org/10.1021/bi901634p

47. Hososhima S, Sakai S, Ishizuka T, Yawo H (2015) Kinetic evaluation of photosensitivity in bi-stable variants of chimeric channelrhodopsins. PLoS One 10:e0119558. https://doi.org/10.1371/ journal.pone.0119558

48. Mountcastle VB (1997) The columnar organization of the neocortex. Brain 120:701-722

49. Maruoka H, Kubota K, Kurokawa R, Tsuruno S, Hosoya T (2011) Periodic organization of a major subtype of pyramidal neurons in neocortical layer V. J Neurosci 31:18522-18542. https://doi.org/10.1523/JNEUROSCI.3117-11.2011

50. Maruoka H, Nakagawa N, Tsuruno S, Sakai S, Yoneda T, Hosoya T (2017) Lattice system of functionally distinct cell types in the neocortex. Science 358:610-615. https://doi. org/10.1126/science.aam6125

51. Yoshimura Y, Dantzker JL, Callaway EM (2005) Excitatory cortical neurons form fine-scale functional networks. Nature 433:868-873. https://doi.org/10.1038/nature03252

52. Oberlaender M, Boudewijns ZS, Kleele T, Mansvelder HD, Sakmann B, de Kock CP (2011) Three-dimensional axon morphologies of individual layer 5 neurons indicate cell type-specific intracortical pathways for whisker motion and touch. Proc Natl Acad Sci USA 108:4188-4193. https://doi.org/10.1073/ pnas. 1100647108

53. Ko H, Cossell L, Baragli C, Antolik J, Clopath C, Hofer SB, Mrsic-Flogel TD (2013) The emergence of functional microcircuits in visual cortex. Nature 496:96-100. https://doi. org/10.1038/nature12015

54. Ishikawa AW, Komatsu Y, Yoshimura Y (2014) Experiencedependent emergence of fine-scale networks in visual cortex. J Neurosci 34:12576-12586. https://doi.org/10.1523/JNEUR OSCI.1346-14.2014

55. Narayanan RT, Udvary D, Oberlaender M (2017) Cell typespecific structural organization of the six layers in rat barrel cortex. Front Neuroanat 11:91. https://doi.org/10.3389/fnana .2017 .00091

56. Feldmeyer D (2012) Excitatory neuronal connectivity in the barrel cortex. Front Neuroanat 6:24. https://doi.org/10.3389/fnana .2012 .00024

57. Naka A, Adesnik H (2016) Inhibitory circuits in cortical layer 5. Front Neural Circuits 10:35. https://doi.org/10.3389/fncir .2016 .00035

58. Molnár Z, Cheung AF (2006) Towards the classification of subpopulations of layer $\mathrm{V}$ pyramidal projection neurons. Neurosci Res 55:105-115. https://doi.org/10.1016/j.neures.2006.02.008

59. Molyneaux BJ, Arlotta P, Menezes JR, Macklis JD (2007) Neuronal subtype specification in the cerebral cortex. Nat Rev Neurosci 8:427-437. https://doi.org/10.1038/nrn2151 
60. Le Bé JV, Silberberg G, Wang Y, Markram H (2007) Morphological, electrophysiological, and synaptic properties of corticocallosal pyramidal cells in the neonatal rat neocortex. Cereb Cortex 17:2204-2213. https://doi.org/10.1093/cercor/bhl127

61. Brown SP, Hestrin S (2009) Intracortical circuits of pyramidal neurons reflect their long-range axonal targets. Nature 457:11331136. https://doi.org/10.1038/nature07658

62. Sato TR, Svoboda K (2010) The functional properties of barrel cortex neurons projecting to the primary motor cortex. J Neurosci 30:4256-4260. https://doi.org/10.1523/JNEUR OSCI.3774-09.2010

63. Morishima M, Kawaguchi Y (2006) Recurrent connection patterns of corticostriatal pyramidal cells in frontal cortex. J Neurosci 26:4394-4405. https://doi.org/10.1523/JNEUR OSCI.0252-06.2006

64. Kawaguchi Y, Kubota Y (1998) Neurochemical features and synaptic connections of large physiologically identified GABAergic cells in the rat frontal cortex. Neuroscience 85:677-701. https:// doi.org/10.1016/S0306-4522(97)00685-4

65. Gupta A, Wang Y, Markram H (2000) Organizing principles for a diversity of GABAergic interneurons and synapses in the neocortex. Science 287:273-278. https://doi.org/10.1126/scien ce.287.5451.273

66. Wang Y, Toledo-Rodriguez M, Gupta A, Wu C, Silberberg G, Luo J, Markram H (2004) Anatomical, physiological and molecular properties of Martinotti cells in the somatosensory cortex of the juvenile rat. J Physiol 561:65-90. https://doi.org/10.1113/jphys iol.2004.073353

67. Silberberg G, Markram H (2007) Disynaptic inhibition between neocortical pyramidal cells mediated by Martinotti cells. Neuron 53(5):735-746. https://doi.org/10.1016/j.neuron.2007.02.012

68. Bush P, Sejnowski T (1996) Inhibition synchronizes sparsely connected cortical neurons within and between columns in realistic network models. J Comput Neurosci 3:91-110 PMID:8840227

69. Bush PC, Mainen ZF (2015) Columnar architecture improves noise robustness in a model cortical network. PLoS ONE 10:e0119072. https://doi.org/10.1371/journal.pone.0119072

70. Otsuka T, Kawaguchi Y (2009) Cortical inhibitory cell types differentially form intralaminar and interlaminar subnetworks with excitatory neurons. J Neurosci 29:10533-10540. https://doi. org/10.1523/JNEUROSCI.2219-09.2009 